\title{
Schizophrenia and the use of alcohol and other drugs: epidemiological profile*
}

\author{
Esquizofrenia e o uso de álcool e outras drogas: perfil epidemiológico
}

\author{
Esquizofrenia y el uso de alcohol y otras drogas: perfil epidemiológico
}

Jássia Lopes Freitas da Silveira' ${ }^{1}$, Roberto Lazzarini de Oliveira ${ }^{1}$, Bárbara Magalhães Viola ${ }^{1}$ Thaís Marques da Silva ${ }^{1}$, Richardson Miranda Machado ${ }^{1}$

This study aimed at characterizing the social demographic and clinical profile of patients with schizophrenia and alcohol and other drugs addiction of a Center of Psychosocial Attention III of the Central-Western region of the State of Minas Gerais, Brazil, from July 1st, 1997 to July 1st, 2013. It is a descriptive, observational and retrospective epidemiological study. The sample consisted of 1618 patients and the main results were: prevalence of male patients (60.4\%) and the age range was 21 30 years old (48.2\%), presented more expressive abuse of alcohol (35.6\%) and cannabinoids (29.5\%) and the most frequent diagnosis of paranoid schizophrenia (41.7\%). Understanding the factors associated to the coexistence of both conditions can provide a basis for the creation of interventional strategies to improve the prognosis of these patients.

Descriptors: Schizophrenia; Substance-Related Disorders; Alcohol-Related Disorders; Marijuana Abuse; Cocaine-Related Disorders.

Este estudo teve como objetivo caracterizar o perfil sociodemográfico e clínico de pacientes esquizofrênicos e dependentes de álcool e outras drogas usuários de um Centro de Atenção Psicossocial III do Centro-Oeste de Minas Gerais, Brasil, no período julho de 1997 a julho de 2013. Configura-se como estudo epidemiológico descritivo, observacional e retrospectivo. A amostra foi composta por 1.618 pacientes e os principais resultados encontrados foram: prevalência do sexo masculino $(60,4 \%)$ e da faixa etária de 21 a 30 anos (48,2\%), abuso mais expressivo de álcool (35,6\%) e de canabinóides (29,5\%) e diagnóstico mais frequente de esquizofrenia paranoide (41,7\%). Compreender os fatores associados a coexistência dessas duas patologias pode fornecer subsídios para a criação de estratégias intervencionistas que visem melhorar o prognóstico desses pacientes.

Descritores: Esquizofrenia; Transtornos Relacionados ao Uso de Substâncias; Transtornos Relacionados ao Uso de Álcool; Abuso de Maconha; Transtornos Relacionados ao Uso de Cocaína.

El objetivo del estudio fue caracterizar el perfil sociodemográfico y clínico de los pacientes con esquizofrenia y dependientes de alcohol y otras drogas, usuarios de un Centro de Atención Psicosocial III, del Centro Oeste de Minas Gerais, Brasil, de julio de 1997 a julio de 2013. Estudio epidemiológico descriptivo, observacional y retrospectivo. La muestra fue de 1.618 pacientes y los principales resultados fueron: prevalencia del sexo masculino $(60,4 \%)$ y de la faja de edad de 21 a 30 años $(48,2 \%)$, abuso más expresivo de alcohol $(35,6 \%)$ y de canabinoides $(29,5 \%)$ y diagnóstico más frecuente de esquizofrenia paranoide (41,7\%). Comprender los factores asociados a la coexistencia de estas dos patologías pude fornecer soportes para creación de estrategias de intervenciones con el fin de mejorar el pronóstico de estos pacientes.

Descriptores: Esquizofrenia; Trastornos Relacionados con Sustancias; Trastornos Relacionados con Alcohol; Abuso de Marihuana; Trastornos Relacionados con Cocaína.

\footnotetext{
*Article produced from the optional subject 'Research in Health' of the Graduation Course in Nursing of the Universidade Federal de São João Del-Rei, Campus Centro-Oeste Dona Lindu, MG, Brazil.

${ }^{1}$ Universidade Federal de São João Del Rei. Divinópolis, MG, Brazil. E-mail: jassialopes@hotmail.com

Corresponding author: Richardson Miranda Machado

Rua São Paulo, 1080, apto 301, Centro. CEP: 35500-006 - Tel: (37) 3222-8147. Divinópolis, MG, Brazil. E-mail: richardson@usp.br
} 


\section{Introduction}

Schizophrenia is a serious mental disorder, stigmatizing and chronic, and it has a multifactorial origin. According to the International Classification of Diseases, $10^{\text {th }}$ edition $^{(1)}$, it can be classified into nine different types, all of them present as a common process the disaggregation of the personality of the patient. Its main manifestation can occur through various symptoms, such as delirium and hallucinations, apathy, isolation, disorder of attention, concentration and memory, anxiety and depression ${ }^{(2)}$.

Schizophrenia is included as one of the main causes of disability among the youths and the adults, attacking approximately $1 \%$ of the world population ${ }^{(3)}$. In Brazil, between August, 2012 and August, 2013, the number of hospitalizations due to schizophrenia reached 93,364 with 364 deaths ${ }^{(4)}$.

Among the causal factors involved, it is known that genetics and the environmental influences have an important role, and the abuse of drugs is considered one of the possible factors which accelerate the disorder ${ }^{(5)}$. It should also be highlighted that several studies showed the importance of this disorder as a cause for the search of $\operatorname{drugs}^{(6)}$. Therefore, the chronical use of alcohol, cannabinoids among other toxic agents can be both an unleashing factor as well as a consequence of psychic condition ${ }^{(7)}$.

It is estimated that approximately $3.5 \%$ of the addicted of alcohol and other drugs have this disorder as an additional psychiatric diagnosis ${ }^{(7)}$. Researches show that the chances of a person being schizophrenic and use drugs are 4.6 times bigger than the rest of the population $^{(8)}$.

The abusive use of these drugs can anticipate the beginning of schizophrenia, exacerbate the psychotic symptoms, reduce the adhesion to the treatment and increase the cognitive deficits, the frequency of relapses, the risk of suicide and acquire infectious and contagious diseases, besides intensifying the violent behavior $^{(9)}$. So, it can be concluded that the abuse of these substances is an aggravating factor regarding the prognosis of the schizophrenic patients, configuring a challenge in the treatment of this disease $\mathrm{e}^{(8)}$.

Among the most used substances by these patients alcohol is outstanding ${ }^{(10)}$. The concomitant occurrence of disorders by the abuse of alcohol and schizophrenia is an indicator of the worst evolution of the disease. Adverse and important consequences are unleashed in its course, with a greater risk of unemployment, decrease of schooling, exacerbation of psychiatric symptoms ${ }^{(11)}$, besides the decrease in the capacity of judgment, negligence regarding the use of medicine and frequent recurrent hospitalization ${ }^{(12)}$.

It is worth highlighting that the schizophrenic patients and alcohol addicted are frequently tobacco smokers, and there is a higher prevalence among these patients when compared to the general population ${ }^{(13)}$. Besides that, they are less prone to quit smoking and have a higher risk of morbidity and mortality related to tobacco. A study observed that $88 \%$ of those were daily smokers and smoked an average of 15 cigarettes a day and $69 \%$ used other drugs, including cocaine (32\%) and occasionally cannabinoids $(47 \%)^{(14)}$.

From 1990 on there were researches showing that the bearers of schizophrenia, are also more prone to use cannabinoids than the population in general ${ }^{(15)}$. Such studies showed that the drug, in most of the times, is associated to exacerbations of the disease and the acute psychotic episodes ${ }^{(10)}$, anticipations of the beginning of the symptoms in 2 to 4 predisposed patients, besides provoking harmful effects in the results and in the clinical course of the disease ${ }^{(16)}$.

Although, in the long term range, the cannabinoids can have severe effects in some users, it was shown that just a minority of these subjects developed psychosis. This low incidence can be attributed to several factors, particularly the degree of exposition to the drug, genetic predisposition, environmental factors of risk and the age of the first use of the cannabinoids ${ }^{(15)}$.

The consumption of drugs, licit or illicit, is frequent among the bearers of schizophrenia. However, the association of these comorbidities and 
the negative effects that one presents on the other are commonly neglected by the health team who offer assistance to this patient. The patient, many times, receives treatment for the most evident pathology, which prevents him of being treated in a whole and effective manner.

This combination can also lead the patient to self-destruction, besides causing behavioral alterations and increasing morbidity and mortality. Such situation represents a serious problem of public health especially due to the difficulty of access to the service of health and because many times there is no adequate treatment or because these patients present resistance to the treatment, which can increase the risks to them ${ }^{(7)}$.

Offering a multidisciplinary treatment, including medical assistance, psychotherapy and nursing care can be a way to minimize the possible negative consequences resulting from the concomitant presence of these two disorders and promote a treatment centered on the patient. So, nursing makes the link between the patient, other professionals and the institutions of health possible. Besides that, these are the caregivers who are more present in the daily contact with these patients, sharing the difficulties, symptoms, complaints and behavior with the other professionals of the health team.

It is known that the number of studies are insufficient to conclude the functioning of the diseasesabuse dynamics of drugs ${ }^{(11)}$. So, epidemiological studies are necessary to enhance the knowledge concerning the negative consequences and the causes of high prevalence of the use of alcohol among the bearers of schizophrenia, as well as other drugs.

Understanding the factors which influence the coexistence of those conditions can improve the prognosis of the patients when subsidizing the creations of interventional strategies for the treatment of the same. For such, the present study is aimed at characterizing the social demographic and clinical profile of schizophrenic patients and addicted to alcohol and other drugs of a center of psychosocial attention.

\section{Method}

It is an epidemiological, descriptive, crosssectional, observational and retrospective study. It is aimed at describing the characteristic of a specific event and establishes relations among variables which characterize the group studied in a pre-established period of time without interference in the event under analysis. The data used refer to past periods ${ }^{(17)}$

The research was made at the Centro de Atenção Psicosocial III (Center of Psychosocial Attention III) in the county of Divinópolis, MG, Brazil. This service works daily, during 24 hours, and it is a reference for the bearers of severe and/or persistent mental disorders and users of drugs, providing assistance to the whole population of the county and to other five neighboring cities, reaching a population of approximately 300 thousand inhabitants. Currently, it offers three modalities of assistance: (1) assistance of rehabilitation, in which the assistance is rendered intensively and varied activities by a multi professional team; (2) assistance of urgency and emergency a psychiatric patient undergoing a crisis, they are sent by the health net or go to the service spontaneously; (3) ambulatory assistance.

The data collection was made through the consultation of the medical records at the Service of Medical and Statistics Archive of the Center of Psychosocial Attention. Based on those information a data bank was made with the following variables: sex, age, origin of the patient for the treatment at the Center of Psychosocial Attention, diagnosis of 
the use of psycho active substance and the type of schizophrenia (according to the International Classification of Diseases ${ }^{(1)}$ ), type of treatment, time of treatment and type of discharge.

The population in this study was made by all the patients bearers of schizophrenia, chemical addicted assisted at the Center of Psychosocial Attention from July $1^{\text {st }}, 1997$ (date of the opening of the service) to July ${ }^{\text {st }}, 2013$ (date of data collection), totaling 16 years and 1,618 patients. The following criteria of inclusion were adopted: 1) diagnosis of schizophrenia and chemical addicted; 2) medical records with complete data; 3) permanence in the Center of Psychosocial Attention III for more than 24 hours; 4) Assistance from admission until discharge, transference or death. For the analysis of the results, the descriptive statistics was used, the Statistical Package for Social Sciences version 11.5 .

The study was approved by the committee of ethics and research of the Universidade Federal of São João del Rei (Legal Opinion no‥339.939/13).

\section{Results}

Tables 1 and 2 present the results obtained in the research.

A total of 14,161 patients were assisted at the Center of Psychosocial Attention from July 1st, 1997 to July 1sr, 2013. Of those 1,618 (11.4\%) had the diagnosis of schizophrenia and use of alcohol and other drugs, being 978 (60.4\%) men and minority were women $(39.6 \%)$.

780 patients were found, $42.8 \%$ sampling, they were between 21 and 40 years of age and this age range was the one which presented a greater occurrence of schizophrenia and use of alcohol and drugs. Of those, most of them were men (71.0\%), while the women were $29 \%$. In both sexes it was less common to be 41 years old or more. But in the patients of the female sex the predominant occurrence happened between 31 and 40 years old and in men from 21 to 40 years of age.
As to the origin of the patients, $665(41.1 \%)$ were sent to the service by their own families, 456 (28.2\%) had court order for refusing the treatment and $364(22.4 \%)$ were referenced through the county emergency room. The minority was referenced through the Family Health Teams (8.2\%). Of the patients sent by their own families, the women are highlighted, representing $64.4 \%$ of these patients. Among men it was more common to be sent through the forum, through a court order, and more rarely through the health team. Among the women, the referral through the Family Health Team was the least common.

Among the most consumed drug, alcohol was the most prevalent, being used by 576 (35.6\%) patients, and followed by the cannabinoids and the tobacco derivatives, representing $29.5 \%$ (478) and $13.5 \%$ (219), respectively. Among the users of alcohol $50.3 \%$ are women and the smallest part is made up by men (49.7\%). Important findings were concerning the bigger consumption of cannabinoids by the patients of the male sex and to the fact that the use of volatile solvents was rare, the same happening among the women.

Of the 1,618 patients, 675 (41.7\%) are bearers of paranoid schizophrenia, followed by the bearers of the simple type $(345 ; 21.3 \%)$. Post-schizophrenia depression, undifferentiated schizophrenia, catatonic schizophrenia and hebephrenic schizophrenia represented the smallest parcel of the sampling with 58 patients (3.5\%). In both sexes, the paranoid schizophrenia was the most frequent and the postschizophrenia depression was the least common, also in both sexes.

Concerning the type of treatment, in the first assistance at the mental health service, 1128 (69.7\%) were sent to receive assistance in an intensive condition (day permanence) and, among those, the patients of the male sex prevailed. The women were more common (60.8\%) among the 490 patients treated in an ambulatory.

A total of 877 (54.2\%) patients were assisted 
Table 1 - Social demographic characterization of origin and the use of alcohol and other drugs by schizophrenic patients assisted in the Center of Psychosocial Attention between 1997 and 2013

\begin{tabular}{|c|c|c|c|}
\hline \multirow[t]{2}{*}{ Variables } & Men & Women & Total \\
\hline & n (\%) & n (\%) & n (\%) \\
\hline Sex & $978(60,4)$ & $640(39,6)$ & $1.618(100.0)$ \\
\hline \multicolumn{4}{|l|}{ Age (years) } \\
\hline $10-20$ & $112(53.8)$ & $96(46.2)$ & 208 (12.9) \\
\hline $21-30$ & $554(71.0)$ & $226(29.0)$ & $780(48.2)$ \\
\hline $31-40$ & $219(47.9)$ & $238(52.1)$ & 457 (28.2) \\
\hline$\geq 41$ & $93(53.8)$ & $80(46.2)$ & $173(10.7)$ \\
\hline \multicolumn{4}{|l|}{ Origin } \\
\hline Family & $237(35.6)$ & $428(64.4)$ & $665(41.1)$ \\
\hline Family Health Teams & $70(52.6)$ & $63(47.4)$ & $133(8.2)$ \\
\hline County Emergency Room & $293(80.5)$ & $71(19.5)$ & $364(22.5)$ \\
\hline Forum (Court Order) & $378(82.9)$ & $78(17.1)$ & $456(28.2)$ \\
\hline \multicolumn{4}{|l|}{ Diagnosis of drug use } \\
\hline F10 - Use of alcohol & $286(49.7)$ & $290(50.3)$ & $576(35.6)$ \\
\hline F11 - Use of opiates & $6(54.5)$ & $5(45.5)$ & $11(0.7)$ \\
\hline F12 - Use of cannabinoids & $361(75.5)$ & $117(24.5)$ & $478(29.5)$ \\
\hline F13 - Use of sedative and hypnotic drugs & $3(12.0)$ & $22(88.0)$ & $25(1.5)$ \\
\hline F14 - Use of cocaine/crack & $93(60.8)$ & $60(39.2)$ & $153(9.5)$ \\
\hline F15 - Use of other stimulants & $4(30.8)$ & $9(69.2)$ & $13(0.8)$ \\
\hline F16 - Use of hallucinogens & $2(33.3)$ & $4(66.7)$ & $6(0.4)$ \\
\hline F17 - Use of tobacco & $121(55.3)$ & $98(44.7)$ & $219(13.5)$ \\
\hline F18 - Use of volatile solvents & $1(33.3)$ & $2(66.7)$ & $3(0.2)$ \\
\hline F19 - Use of multiple drugs & $101(75.3)$ & $33(24.7)$ & $134(8.3)$ \\
\hline
\end{tabular}

for a period from 31 to 60 days, being $58.5 \%$ men. Among the women the time of treatment from 31 to 60 days was also the most common.

The types of discharge were obtained through the last register assistance of each patient. The medical discharges were more frequent (46.6\%), and the minority of the patients received discharge due to the transference to another clinic $(1.0 \%)$. The results by sex was quiet divergent, once most men ended their treatment due to abandon or evasion, while in the women the highest occurrence was observed in the discharges provided by the assistant doctors.

\section{Discussion}

It is known that schizophrenia attacks mainly the men, which can be partly explained by the precocity of the occurrence of the symptoms: the peak of the beginning of the symptoms occurred between 15 and 25 years of age in men and between 25 and 35 years in the women ${ }^{(18)}$. The results obtained in this study agree with the literature, both regarding the greater use and abuse of alcohol and other drugs by the male $\operatorname{sex}^{(8)}$, as well as concerning the epidemiology of the schizophrenia. 
Table 2 - Characterization of the clinical treatment and diagnosis of the type of schizophrenia of the patient users of alcohol and other drugs assisted at the Center of Psychosocial Attention of the county under study between 1997 and 2013

\begin{tabular}{|c|c|c|c|}
\hline \multirow{2}{*}{ Variables } & Men & Women & Total \\
\hline & n (\%) & n (\%) & n (\%) \\
\hline \multicolumn{4}{|l|}{ Diagnosis of schizophrenia } \\
\hline F20.0 - Paranoid schizophrenia & $468(69.3)$ & $207(30.7)$ & 675 (41.7) \\
\hline F20.1 - Hebephrenic schizophrenia & $11(61.1)$ & $7(38.9)$ & $18(1.1)$ \\
\hline F20.2 - Catatonic schizophrenia & $8(53.3)$ & $7(46.7)$ & $15(0.9)$ \\
\hline F20.3 - Undifferentiated schizophrenia & $11(50.0)$ & $11(50.0)$ & $22(1.4)$ \\
\hline F20.4 - Post-schizophrenic depression & $1(33.3)$ & $2(66.7)$ & $3(0.2)$ \\
\hline F20.5 - Residual schizophrenia & $102(47.9)$ & $111(52.1)$ & $213(13.2)$ \\
\hline F20.6 - Simple schizophrenia & $170(49.3)$ & $175(50.7)$ & $345(21.3)$ \\
\hline F20.8 - Other types schizophrenia & $145(71.4)$ & $58(28.6)$ & $203(12.5)$ \\
\hline F20.9 - Non-specified schizophrenia & $62(50.0)$ & $62(50.0)$ & $124(7.7)$ \\
\hline \multicolumn{4}{|l|}{ Type of treatment } \\
\hline Ambulatory & $192(39.2)$ & $298(60.8)$ & $490(30.3)$ \\
\hline Day permanence & $786(69.7)$ & $342(30.3)$ & $1128(69.7)$ \\
\hline \multicolumn{4}{|l|}{ Time of treatment (days) } \\
\hline 1 a 30 & $261(58.4)$ & $186(41.6)$ & $447(27.6)$ \\
\hline 31 a 60 & $513(58.5)$ & $364(41.5)$ & $877(54.2)$ \\
\hline$>60$ & $204(69.4)$ & $90(30.6)$ & $294(18.2)$ \\
\hline \multicolumn{4}{|c|}{ Type of discharge of Center of Psychosocial Attention } \\
\hline Medical discharge & $307(40.7)$ & $447(59.3)$ & $754(46.6)$ \\
\hline Requested discharge & $270(98.9)$ & $3(1.1)$ & $273(16.9)$ \\
\hline Discharged by abandon/evasion & $395(68.7)$ & $180(31.3)$ & $575(35.5)$ \\
\hline Clinical transference & $6(37.5)$ & $10(62.5)$ & $16(1.0)$ \\
\hline
\end{tabular}

In the general population, studies showed that the main beginners and the users who consume more alcohol and other drugs are the older adolescents and the young adults. The use of drugs usually starts before 18 years of age, in most of the times it becomes abusive between 19 and 23 years of age and tends to decrease near 30 years of age. According to the Brazilian Reports on Drugs, published in 2009, the age range between 18 and 24 years was the one which presented the highest rates of chemical addiction followed by the age range between 25 to 34 years, and this data are valid for both sexes ${ }^{(19)}$.

The bearers of schizophrenia are also exposed to all the biological, social and psychological alterations which are characteristic of the phase of transition from adolescence to the adult life. So, many times they use drugs as a way to escape from the social conditions to which they are submitted in this phase and aim at minimizing the characteristics symptoms of the disease and the adverse aspects resulting from the medication ${ }^{(11)}$. Such fact can justify the reason why these patients are 4.6 times more prone to using substances of abuse than the population in general ${ }^{(8)}$.

As to the origin of patients, it was observed that great part of the sample was sent to the services by their own families, while the minority was referenced 
through the Family Health Team. Such findings reflect how much the primary attention has to be improved specifically concerning the care of these patients.

Several factors can justify the fact that the bearers of schizophrenia who use drugs face difficulties to receive effective care through the Family Health Teams, among them: difficulties of communication, cognitive jeopardizing resulting from the disorder, lack the training of the team for the handling of these patients, lack of resources and professionals, absence of preventive measures to avoid the abusive use of alcohol and other drugs, the small area of national territory which is assisted by these teams, the great demand of the clientele through which each one is responsible and the lack of integration among the several services and among the levels of attention to health. As a consequence, this group is subject to being sent to more specialized services by their own family who also see themselves helpless in this process $^{(20-21)}$. In this sense, analyzing the distribution by sexes, it was found that most men were sent to the service by the forum, reinforcing the idea that men are more resistant to the treatment.

Regarding the diagnosis of the type of schizophrenia, it was noticed that the paranoid was the most prevalent in both sexes. Such finding was already expected by the fact that this type is the most common in many parts of the world. The main symptoms are deliriums relatively stable, generally associated to hallucinations and disorders of the perception. Alterations of affection, volition and speech and catatonics symptoms can be present, but they do not dominate the picture ${ }^{(1)}$.

Here, it is worth bringing the hypothesis that the typical clinic picture together with its prevalence can explain the fact that almost half of the samples was diagnosed as bearers of the paranoid type, and there is a possible relation between the symptoms and the search for drugs. However, there is a lack of studies in the literature which deal with the prevalence of types of schizophrenia to allow such association.

Still on the diagnosis of the type of schizophrenia, another result obtained deserves attention. The simple type is an uncommon disorder and it has difficult diagnosis, but it emerges as the second most prevalent in this study. It is characterized by an insidious and progressive development of strange behavior, difficulty to follow the requirement of the society and jeopardizing the total performance. The deliriums and hallucinations are not frequent and this is a less psychotic type ${ }^{(1)}$. Facing this finding, it is worth reflecting whether they are psychotic symptoms characteristic of this disorder, the main reason for the abuse of drugs or whether it is the social commitment which occurs as a consequence of this disorder.

In this research, it was noticed that alcohol among other substances was the most consumed. After that are the cannabinoids, followed by tobacco. These results partially agree with other researches once in these the most used drugs by schizophrenic patients are also alcohol and cannabinoids but after that comes cocaine ${ }^{(10)}$. However, other studies review that schizophrenic patients and alcohol addicted are frequently tobacco smokers and there seems to be a certain genetic association among these factors ${ }^{(13)}$.

Considering the analysis by sex, the use of cannabinoids prevailed among men, and the consumption of alcohol was slightly bigger among women. Such results appear as a surprise once the literature show that alcohol is the main drug consumed by men and they use it independently of the age range, more than the women ${ }^{(8,19)}$.

There are several possible causes which justify the abuse of alcoholic drinks by schizophrenic patients and among the main determinants; there is the search for social integration, pleasure and leisure, besides the self-treatment of the positive, depressive and psychotic symptoms. Despite of that, the use of alcohol by these patients can be impactful, causing symptoms of anxiety and sleep disorders, which result in the increase of prescriptions of benzodiazepines, enhancing the risk of developing the abuse and addiction of these drugs ${ }^{(11)}$.

Some studies show that patients, bearers of 
schizophrenia are more prone to using cannabinoids than the populations in general. The continued use of cannabis is associated to a bad prognostic in patients with existing psychotic diseases ${ }^{(15)}$. It has already been described that its use by healthy subjects who started the use of cannabinoids approximately around 18 years of age presented double the potential risk to develop a psychotic disorder in the subsequent 15 years. Besides that, a relation dose-response was observed, in which the heavy users of these substances were six times more predisposed than the non-users to receive a diagnosis of schizophrenia later on ${ }^{(15)}$.

Concerning tobacco smoking, the researches show that the prevalence among the people with schizophrenia is $58-90 \%$. Although the exact causes are unknown a variety factors such as the gratification for good behavior in the closed institutions of treatment, boredom, the decrease of the secondary effect of the negative psychotics symptoms and the self-medication can be involved. Another interesting aspect is that these patients tend to be heavier smokers than the smokers in the population in general, which reflects a greater morbidity and mortality. Despite these increased risks, the rates of quitting tobacco among these patients are still low, especially among the patients treated with first generation of antipsychotic drugs ${ }^{(8)}$.

Considering the type of treatment, in both sexes, the present study showed a higher occurrence of treatment in services of day-permanence, when compared to the patient assisted in an ambulatory. But, there was a relatively higher frequency among men. Such finding reinforces, once again, the resistance and refusal of these patients to the treatment, once this type of treatment is better supervised and increases the chances of a better adhesion.

The services of day-permanence offer care in mental health which are less restrictive than hospitalization, however, they are more intense than ambulatory assistance, working as a transition between the two ${ }^{(22)}$. This way of treatment has as one of its main objectives the psychosocial rehabilitation through the Therapeutic Workshops and each one has a therapist responsible for the activities and techniques which lead to a process of coexistence among the patients, mediating the process of social reinsertion ${ }^{(23)}$. Through this methodology, the chances of permanent hospitalization are smaller and there is a lower rate of unemployment, besides constituting an option of extreme importance for the patients who are resistant to the treatment and the ones who need long term care $^{(22)}$.

Despite the advantages of the day-permanence treatment, some studies do not identify a significant difference in the assistance of subjects treated in an ambulatory and in the day-permanence condition, thus making ambulatory assistance more advantageous for presenting lower $\operatorname{cost}^{(22)}$. However, it is common among these patients, the non-attendance to the appointments during the ambulatory treatment and this is probably associated to demographic variables, clinic picture and other factors ${ }^{(24)}$.

Considering the total time of the treatment, it was observed that the results found in this study are in consonance with the data found in the literature. A Brazilian study which evaluated 2,247 hospitalizations, made evident that the average time of hospitalization due to schizophrenia was 29.64 days and due to disorders related to the abuse of alcohol was 27.11 days. The period of treatment of the schizophrenic patients with abuse of alcohol or other drugs is influenced by several factors, among them the chronicity of the picture, thus requiring a longer period of treatment ${ }^{(25)}$.

The researches show that approximately $60 \%$ of the bearers of schizophrenia do not adhere completely to the treatment. Such fact can be related in the process of the diseases which, because it presents a chronic character, requires prolonged and prophylactic (non-curative) treatment and that many times does not guarantee a satisfactory response as well as the factors which are directly linked to the patient, such as the adverse effects of the medication, difficulty to remember to take the medicine and the 
lack of knowledge regarding the disease itself. The non-adhesion is still associated to the increase of the chances of relapses and re-hospitalization, a worse prognostic and greater costs ${ }^{(3)}$.

Analyzing the data found in this research regarding the type of discharge of the Center of Psychosocial Attention, it was observed that, despite the fact that these was an expressive number of patients who had quit their work, the majority received medical discharge. These results can be opposite to what had been stated before, reflect a better adhesion to the treatment, also contesting the findings of the literature.

However, analyzing the genders separately, it was noticed that the discharge caused by abandon/ evasion predominated among men, which again contributes to the idea of opposition to the treatment by a part of this gender, even despite the care rendered by the reference service during the period of permanence, aiming at improving the symptoms provoked by the disease, although it does not necessarily guarantee an improvement in the quality of life. It should be highlighted that the variables here analyzed do not allow evaluating whether a long term adhesion is present in those patients assisted by the Center of Psychosocial Attention.

\section{Conclusion}

The present work highlights, in accordance with the literature, the great relevance of the study of the association between the use of alcohol and other drugs and the schizophrenia. Just like in most of the studies, it was evident that the most attacked ones are young men, and the most common is the paranoid schizophrenia and the most widely used drugs by the population is alcohol and the cannabinoids. It is worth highlighted that in the analysis of the genders, it was evident the great resistance of men to search and adhere to the treatment.

As it has already been highlighted, the concomitance of schizophrenia with abuse of psycho- active substance is extremely harmful to the patient, his family and the community, once it reduces the adhesion to the treatment, negatively influences the action of the anti-psychotic drugs and worsens the symptoms, which aggravates the prognosis and increase the mobility and mortality. So it is essential that the services of attention to mental health have a vigilant posture concerning the schizophrenic patients, in order to avoid their access to drugs and to treat those who already have these disorders such as alcoholics and drug addiction.

In these sense, it is convenient that such services should elaborate strategies to narrow the link of the patients with the venue of the treatment and reduce the percentages of quitting, in order to avoid that the patients search for alcohol and other drugs with the objective to reduce their symptoms. The Centers of Psychosocial Attention then become key pieces concerning the full adhesion to the treatment, once, when adequately structured; those services tend to keep the patient under treatment voluntarily. This naturally makes the link with the team become narrower than when compared to other hospital of ambulatory service. Besides that, actions of education in health aiming at the prevention and ceasing of tobacco smoking can be effective.

The abuse of illicit drugs can be a predisposing factor for the occurrence of psychotic symptoms, it would be valuable to provide its prevention in the whole population as a way to prevent or minimize the picture of schizophrenia. Under this perspective, it is understood that the units of primary attention to health are important in the actions of prevention of the use and abuse of drugs and also the assistance to the patients under greater risk. However, it is known that this scope of attention is responsible for the minority of the references.

\section{Collaborations}

Silveira JLF, Oliveira RL, Silva TM and Viola $\mathrm{BM}$ contributed for the conception and elaboration 
of the project, analysis and data collection, writing of the article and final approval of the version to be published. Machado RM participated in the conception and elaboration of the project, data analysis, writing of the article and the final approval of the version to be published.

\section{References}

1. International Statistical Classification of Diseases and Related Health Problems 10th Revision - ICD10. Version: 2010. [Internet] 2010 [cited 2013 Nov 13]. Available from: http://apps.who.int/ classifications/icd10/browse/2010/en

2. Arantes-Gonçalves F, Marques JG, Coelho R. O papel da apoptose na esquizofrenia. Psiquiatr Clín. 2012; 33(1):5-15.

3. Nicolino PS, Vedana KGG, Miasso AI, Cardoso L, Galera SAF. Schizophrenia: adherence to treatment and beliefs about the disorder and the drug treatment. Rev Esc Enferm USP. 2011; 45(3):708-15.

4. Ministério da Saúde (BR). Informações de saúde - epidemiológicas e morbidade [Internet] 2008 [citado 13 Nov 2013]. Disponível em: http://www2.datasus.gov.br/DATASUS/index. php?area $=0203 \&$ VObj=http://tabnet.datasus. gov.br/cgi/deftohtm.exe?sih/cnv/nr

5. Gururajan A, Manning E, Klug M, Buuse M. Drugs of abuse and increased risk of psychosis development. Aust N Z J Psychiatr. 2012; 46(12):1120-35.

6. Asher CJ, Gask L. Reasons for illicit drug use in people with schizophrenia: Qualitative study. BMC Psychiatr. 2010; 10(94):1-15.

7. Scheffer M, Pasa GG, Almeida RMM. Dependência de álcool, cocaína e crack e transtornos psiquiátricos. Psicol Teor Pesq. 2010; 26(3):53341.

8. Mackowick KM, Heishman SJ, Wehring HJ, Liu F, McMahon RP, Kelly DL. Illicit drug use in heavy smokers with and without schizophrenia. Schizophr Res. 2012; 139(1-3):194-200.

9. De Hert $M$, Wampers $M$, Jendricko $T$, Franic $T$, Vidovic D, De Vriendt N, et al. Effects of cannabis use on age at onset in schizophrenia and bipolar disorder. Schizophr Res. 2011; 126(1-3):270-6.

10. Kelly TM, Daley DC, Douaihy AB. Treatment of substance abusing patients with comorbid psychiatric disorders. Addict Behav. 2012; 37(1):11-24.

11. Thornton LK, Baker AL. The importance of investigating alcohol use among people with schizophrenia [Abstract]. Acta Psychiatr Scand. 2013; 128(1):96.

12. Lin $\mathrm{CH}$, Huang $\mathrm{CJ}$, Huang $\mathrm{YH}$, Chen $\mathrm{CC}$. Time to rehospitalization of schizophrenia patients with alcohol use disorders. Acta Psychiatr Scand. 2013; 128(1):94-5.

13. Nikolac M, Sagud M, Nedic G, Nenadic KS, Mihaljevic AP, Uzun S, et al. The lack of association between catechol-O-methyl-transferase Val108/158Met polymorphism and smoking in schizophrenia and alcohol dependence. Psychiatr Res. 2013; 205(12):179-80.

14. Meszaros ZS, Dimmock JA, Ploutz-Snyder R, AbdulMalak Y, Leontieva L, Canfield K, et al. Predictors of Smoking Severity in Patients with Schizophrenia and Alcohol Use Disorders. Am J Addict. 2011; 20(5):462-7.

15. Casadio P, Fernandes C, Murray RM, Di Forti M. Cannabis use in young people: the risk for schizophrenia. Neurosci Biobehav Rev. 2011; 35(8):1779-87.

16. Sugranyes G, Flamarique I, Parellada E, Baeza I, Goti J, Fernandez-Egea E, et al. Cannabis use and age of diagnosis of schizophrenia. Eur Psychiatry. 2009; 24(5):282-6.

17. Marconi MA, Lakatos EM. Técnicas de Pesquisa. 7aㅡ ed. São Paulo: Atlas; 2011.

18. Mura G, Petretto DR, Bhat KM, Carta MG. Schizophrenia: from epidemiology to rehabilitation. Clin Pract Epidemiol Ment Health. 2012; 8:52-66.

19. Secretaria Nacional de Políticas sobre Drogas (BR). Relatório Brasileiro sobre Drogas IMS/USP. Brasília: SENAD; 2009.

20. Cahoon EK, McGinty EE, Ford DE, Daumit GL. Schizophrenia and potentially preventable hospitalizations in the United States: a 
retrospective cross-sectional study. BMC Psychiatr. 2013; 13(37):1-8.

21. Martins AKL, Braga VAB, Souza AMA. Práticas em saúde mental na Estratégia Saúde da Família: um estudo bibliográfico. Rev Rene. 2009; 10(4):16572.

22. Shek E, Stein AT, Shansis FM, Marshall M, Crowther R, Tyrer P. Day hospital vs outpatient care for people with schizophrenia. Schizophr Bull. 2009; 35(6):1057-8.

23. Werneck B. Hospital-dia e acompanhamento terapêutico: trabalhos essenciais em saúde mental. Psychiatr on Line Brasil. [periódico na Internet] 2009 [citado 2014 Jan 25];14(10). Disponível em: http://www.polbr.med.br/ano09/ pcl1109.php

24. Adelufosi AO, Ogunwale A, Adeponle AB, Abayomi 0 . Pattern of attendance and predictors of default among Nigerian outpatients with schizophrenia. Afr J Psychiatry. 2013; 16(4):283-7.

25. Souza JC, Souza N, Magna LA. Tempo médio de hospitalização e categorias diagnósticas em hospital psiquiátrico. J Bras Psiquiatr. 2008; 57(2):112-6. 